\title{
In vitro and in vivo evaluation of colon cancer targeted epichlorohydrin crosslinked Portulaca-alginate beads
}

https://doi.org/10.1515/bmc-2018-0019

received October 5, 2018; accepted December 3, 2018.

Abstract: The aim of this study was to formulate a novel dual crosslinked hydrogel bead using Portulaca mucilage for colon-targeted delivery of 5-fluorouracil (5-FU) and evaluate its safety, specificity and efficacy. The ionotropic gelation technique was employed to prepare the hydrogel beads of Portulaca mucilage. For this, the mucilage was initially crosslinked with alginate and calcium ions. Epichlorohydrin was employed as a crosslinker in the second crosslinking step. The formulation was subjected to in vitro and in vivo studies to evaluate morphology, size, cytotoxicity, and organ distribution. Human HT-29 colon cancer cell-line was used for in vitro assays and in vivo studies were performed in Wistar rats to assess the usefulness and effectiveness of the formulation for colon cancer therapy. Microsphere sizes ranged from 930 to $977 \mu \mathrm{m}$ and possessed a high level of drug encapsulation efficiency (ca. 78\% w/w). Compared with 5-FU solution $\left(\mathrm{T}_{\max }=1.2 \mathrm{~h}\right.$, mean resident time: $\left.\mathrm{MRT}=3.3 \mathrm{~h}\right)$ the dual crosslinked Portulaca microspheres exhibited sustained drug release after oral administration to rats $\left(\mathrm{T}_{\max }=16 \mathrm{~h}\right.$, MRT $=14 \mathrm{~h}$ ). The relative bioavailability of 5-FU solution and the microspheres were 100 and $93.6 \%$ respectively. Tissue distribution studies indicated high concentration of 5-FU in colon. In-vitro anticancer assay demonstrated IC $_{50}$ value of $11.50 \mu \mathrm{g} / \mathrm{ml}$ against HT-29 colon cancer cell line. The epichlorohydrin cross-linked Portulaca microspheres prepared in this study provided sustained release of

\footnotetext{
*Corresponding author: Geet P. Asnani, Sinhgad Technical Education Society's, Smt. Kashibai Navale College of Pharmacy, Kondhwa, Pune - 411 048, (affiliated to: Savitribai Phule Pune University), Maharashtra, India, E-mail: soohindab9@gmail.com Chandrakant R. Kokare: Sinhgad Technical Education Society's, Smt. Kashibai Navale College of Pharmacy, Kondhwa, Pune - 411 048, (affiliated to: Savitribai Phule Pune University), Maharashtra, India; Sinhgad Technical Education Society's, Sinhagad Institute of Pharmacy, Narhe, Pune - 411 041, (affiliated to: Savitribai Phule Pune University), Maharashtra, India
}

5-FU up to $16 \mathrm{~h}$ in the colonic region and enhanced the antitumor activity of the neoplastic drug. The formulation is hence an ideal carrier system for colon-targeted drug delivery.

Keywords: Portulaca oleracea; mucilage; natural polysaccharide; colon targeting; 5-fluorouracil; beads; ionotropic gelation.

\section{Introduction}

The second largest non-communicable disease is cancer - a devastating illness that continues to cause morbidity and mortality worldwide. Patients suffering from different malignancies, including colorectal cancer, are treated with chemotherapy $[1,2]$. One of the generally employed chemotherapeutic agents is 5-fluorouracil (5-FU), which is employed in this study as a model water-soluble antineoplastic drug. As a pyrimidine antimetabolite, 5 -FU is the most widely used anticancer agent known to act by inhibiting thymidylate synthase [3, 4]. Currently, 5-FU is being given to patients predominantly by the intravenous (i.v.) route of drug administration although oral administration is widely preferred over i.v. treatment due to its patient compliance. However, when given orally, the drug has problems of erratic absorption, inconsistent dosing and side effects $[5,6]$. In addition, the half-life of 5-FU in plasma is only 10-20min, and as such high doses (up to $600 \mathrm{mg} / \mathrm{m}^{2}$ weekly) have to be administered to reach therapeutic drug levels $[7,8]$. Previous reports suggest that due to random distribution in tumor and healthy tissues, 5-FU induced toxic side effects in the gastrointestinal tract and bone marrow [9]. It has also resulted in myelotoxicity and stomatitis [10], gut mucosa toxicity [11] and severe neurotoxicity reactions in the brain [12]. Consequently, it is crucial to find efficient targeting strategies to enhance bioavailability, decrease the required dose and protect healthy tissues from harmful side effects. To meet 
this objective, different 5-FU dosage forms have been formulated, which include transdermal patch [13] and water in oil emulsions [14]. Furthermore, different research groups have been trying to increase the therapeutic efficacy of 5-FU and reduce its side effects by employing vesicular phospholipid gels [15], nanoliposomes [16] and tocosome technology [17] and optimizations particularly with respect of safety and stability concerns are ongoing.

In the case of addressing colon cancer, numerous methods have been reported to target drugs to colon. These include prodrugs, $\mathrm{pH}$-responsive strategies, sustained-release formulations, microbial-activated systems, and intestinal-pressure colon delivery capsules [18-21]. The wide $\mathrm{pH}$ range of gastro intestinal (GI) tract poses a challenge to the delivery of therapeutic agents to the colon. Many enteric coating techniques have been attempted thus far to address problems associated with drug delivery to colon [22-26]. In the present research, Portulaca (Purslane) is used as an oral delivery matrix for targeting 5-FU to the colon. It is a novel source of natural polysaccharide, which is soluble or swellable in acidic pH environments while it does not swell in neutral or alkaline $\mathrm{pH}$ media. $\mathrm{pH}$ independent swelling characteristic was imparted to Portulaca by cross-linking with sodium alginate followed by dual crosslinking with epichlorohydrin to prolong the release of 5-FU in vivo. Such cross-linking with epichlorohydrin has several inherent advantages as it is biocompatible and is devoid of toxic side effects [27].

Microspheres crosslinked with epichlorohydrin are among the most efficient drug delivery systems which can be used for targeting 5-FU to colon cancer. These formulations were manufactured through ionotropic gelation technique [28]. Hydrophilic crosslinked polymeric beads were prepared using sodium alginate and Portulaca mucilage (PM), which was extracted from the leaves of Purslane (of the plant family Portulacaceae). This natural mucilage can be a potential excipient to overcome the issues of biocompatibility and biodegradability. Moreover, the polysaccharides present in the mucilage of the leaves can be modified with the aim of adapting their physicochemical properties towards targeting ability, improved loading capacity, stability and scalability. However, the hydrophilic and swelling behavior of PM results in unpredicted drug release from the microspheres. In order to address this issue, epichlorohydrin was utilized in order to control the release of 5-FU specifically in the colon. Epichlorohydrin is known as bifunctional alkylating agent and is being used in the formulation of drug carrier systems composed of mucilages [29-31].
Portulaca Mucilage is hydrophilic in nature and is capable of increasing the drug entrapment efficiency of the microbeads. It is hypothesized that the hydrophilic polysaccharide-based crosslinked particulate drug carriers such as beads have the advantages that they pass uniformly through the gastrointestinal tract with a predictable release profile [32]. In the present study, 5-FU-loaded beads were prepared using a hydrophilic polymer matrix containing a mixture of the two polysaccharides. Sodium alginate, a linear polysaccharide isolated from seaweed, is composed of oxidized sugar units joined together to form an ionic polymer [33]. The presence of negatively charged - $\mathrm{COO}$ side chains and $-\mathrm{OH}$ groups make this natural polysaccharide extremely hydrophilic. Replacing the sodium ions of sodium alginate with calcium ions leads to cross-linking between the polymer chains and consequently results in the formation of an insoluble gel i.e. calcium alginate [33]. Recently, it has been reported that single crosslinked formulations show premature drug release [34]. Consequently, in order to extend the release of drug in the colon the single crosslinked beads were crosslinked again using epichlorohydrin (a bifunctional alkylating agent). The freely available $-\mathrm{COOH}$ and $\mathrm{OH}$ functional groups in the Portulaca mucilage act as crosslinking sites and can form diether linkages with epicholorohydrin thus forming stable beads, which are dual crosslinked with epicholorohydrin. The microsphere formulations were characterized in terms of their morphology and particle size by using SEM technique. In vitro cytotoxicity of the formulations was assessed using the Human colon cancer cell-line (HT-29). In vivo pharmacokinetic evaluations were performed in Wistar rats to understand the effectiveness of the formulated hydrogel beads for colon cancer therapy.

\section{Materials And Methods}

\section{Materials}

Fresh leaves of Portulaca oleracea (Purslane) were collected from Phursungi Village (Pune, India) in the month of June. The anticancer drug 5-FU was purchased from Sigma Aldrich Co. (USA). Sodium alginate (90-180 molecular weight $=216.121)$ was procured from S.D. Fines (Mumbai, India). Epichlorohydrin and calcium chloride were purchased from Sigma Chem. Ltd. (New Delhi, India). Solvents, i.e. ethanol and acetone, were of analytical grade and product of Merck Ltd. Co. (India). 


\section{Isolation of mucilage}

A quantity of $1 \mathrm{~kg}$ of Portulaca oleracea (Purslane) leaves were weighed and then dried at $40^{\circ} \mathrm{C}$. Dried leaves were powdered using a blender and then boiled in $1 \mathrm{~L}$ of $\mathrm{dH}_{2} \mathrm{O}$ at $100^{\circ} \mathrm{C}$ while stirring to form a slurry. The slurry was cooled and filtered using a muslin cloth and kept in refrigerator $\left(4^{\circ} \mathrm{C}\right)$ for a 12 -hour period. The obtained solution was decanted and then boiled to decrease the volume to half and afterwards left to cool down at room temperature. In the next stage, acetone was poured on the obtained solution for three times to assist the precipitation of the mucilage, which was then air dried at room temperature for 24 hours. The dried flakes obtained at this stage were then grinded to fine powder and stored in an airtight container until further use.

\section{Preparation of single crosslinked Portulaca- alginate hydrogel beads}

For the preparation of single-crosslinked hydrogel beads, encapsulating 5-FU, the simple ionotropic gelation technique was employed [35]. The process involved crosslinking of sodium alginate and Portulaca mucilage by the mediation of calcium ions (using 3\% aqueous solution of calcium chloride). The mixing ratio of sodium alginate and Portulaca mucilage was 2.0:1.0 (w/w). A blend of the polymeric solution (containing mixture of sodium alginate and Portulaca mucilage) was prepared in $100 \mathrm{ml}$ volume using distilled water $\left(\mathrm{dH}_{2} \mathrm{O}\right)$. The watersoluble anticancer drug $5-\mathrm{FU}(1 \% \mathrm{w} / \mathrm{v})$ was added to the polymeric solution and the mixture was stirred at 500rpm for 1 hour using a magnetic stirrer at room temperature. The resultant solution was bath sonicated, in order to remove gas bubbles, and was then dropped from a $23 \mathrm{G}$ needle at a $5 \mathrm{~cm}$ height into calcium chloride solution $(2 \% \mathrm{w} / \mathrm{v})$. The hydrogel beads were obtained and excess calcium chloride was removed by washing with $\mathrm{dH}_{2} \mathrm{O}$ and air dried overnight at $30^{\circ} \mathrm{C}$ according to a previously reported procedure [36].

\section{Preparation of double crosslinked Portulaca- alginate hydrogel beads}

Double crosslinked hydrogel beads were prepared as follows: the single crosslinked hydrogel beads, in their wet state, prepared in the previous stage, were immersed into $100 \mathrm{ml}$ sodium hydroxide solution $(2 \mathrm{~N})$ and stirred gently at $40^{\circ} \mathrm{C}$ for 1.5 hours. Then, 10 gr epichlorohydrin was added and the beads were stirred at ca. 20rpm for 24 hours at room temperature. Epichlorohydrin is known as a bifunctional alkylating agent [29-31], and was employed in the formulation as a second crosslinking agent. The hydrogel beads obtained at this stage were in the semisolid state. The hydrogel beads were collected and air-dried overnight at $30^{\circ} \mathrm{C}$ as explained by Awasthi and co-workers [37].

\section{Determination of encapsulation efficiency and percentage yield}

The double-crosslinked hydrogel beads were accurately weighed (equivalent to $100 \mathrm{mg}$ of $5-\mathrm{FU}$ ), powdered and were then bath sonicated in $250 \mathrm{ml}$ of phosphate buffer ( $\mathrm{pH}$ 7.4). The solution obtained was passed through $0.45 \mu \mathrm{m}$ membrane filters. After performing appropriate dilutions, the content of the filtrate was determined using a UV-Vis spectrophotometer (Shimadzu-1800, Japan), by measuring the absorbance of $5-\mathrm{FU}$ at $266 \mathrm{~nm}$ in comparison to the constructed calibration curves. The percentage yield of hydrogel bead manufacture and drug encapsulation efficiency (i.e. incorporation efficiency) were calculated using the following two equations respectively:

$$
\begin{gathered}
\text { Yield }(\%)=\frac{\text { weight of dry beads }}{\text { weight of drug and polymers }} \times 100 \\
\text { Drug incorporation efficiency }(\%)=\frac{\text { Actual drug content in beads }}{\text { Amount of drug added }} \times 100
\end{gathered}
$$

\section{Morphology and particle size analysis}

The double-crosslinked hydrogel beads were characterized morphologically through scanning electron microscope (SEM; JEOL Model JSM - 6390LV, Tokyo, Japan). The hydrogel beads were coated with silver (as a conductive material) using a high-vacuum evaporator (Polaron system) under argon atmosphere by mounting the sample on metal grids. Particle size analysis of the hydrogel beads was performed using the Image J software (version 1.8.0_112).

\section{Cytotoxicity studies}

The cytotoxicity studies were performed using the HT-29 Human colon cancer cell line. Cells were seeded in 96-well plates at the densities of $1 \times 10^{4}$ cells per well containing $0.1 \mathrm{ml}$ medium each and allowed to adhere to the plates by 
incubating them for a period of 24 hours in a $\mathrm{CO}_{2}$ incubator (Eppendorf, New Brunswick, Galaxy 170R, Germany). The incubator was maintained at $37^{\circ} \mathrm{C}$ and $95 \%$ humidity. Cell counts were performed by using the ELISA reader (Model 550, Bio-Rad Laboratories Inc., CA, USA). The cell culture medium was replaced with fresh medium containing the microbead formulation encapsulating $0.1 \mathrm{ml}$ of $5-\mathrm{FU}$ $(25 \mathrm{~g} / \mathrm{ml})$, or control samples (Portulaca mucilage and un-encapsulated 5-FU), and incubated at $37^{\circ} \mathrm{C}$ for $24 \mathrm{hrs}$. At the end of $24 \mathrm{hrs}$ the medium in each well was replaced with $50 \mu \mathrm{l}$ of the MTT solution $(5 \mathrm{mg} / \mathrm{ml}$ in phosphate buffer saline) and the plate was incubated at $37^{\circ} \mathrm{C}$ for 4 hrs. In the next stage, $100 \mu \mathrm{l}$ of dimethyl sulfoxide (DMSO) was used to dissolve the formed formazan crystals in each well. The absorbance was recorded at 570nm filter using an immunosorbent assay (ELISA) plate reader (Lisa Plus, India). Cell viability percent was calculated using the following equation $[38,39]$ :

\author{
Percent cell viability $=$ Absorbance of treated \\ cells /Absorbance of untreated (control cells) X 100
}

\section{In vivo drug absorption assay}

The efficacy of 5-FU encapsulated hydrogel beads for local release to colon site was assessed in a rat model by comparing with a control treatment. The protocols for in vivo study were approved by the Institutional Animal Ethics Committee (with the ethics committee approval number: SKNCOP/IAEC/120/2017). Animals were fasted for 12 hours overnight before the studies and water was available ad libitum during the experiments. Rats were divided into three groups of six animals each. Group I was kept as control and rats were given normal saline, Group II received 5-FU immediate release (IR) formulations prepared by suspending the drug in $0.5 \% \mathrm{w} / \mathrm{v}$ sodium carboxymethyl cellulose (SCMC), and Group III received 5-FU-loaded microspheres. The dose of administered 5-FU was calculated according to surface area of rat's colon $(0.0023 \times 500 \times 7=8.05 \mathrm{mg})$ [40]. Animals were given corresponding formulations containing equivalent of $8.05 \mathrm{mg}$ of $5-\mathrm{FU}$ by oral route. A $0.5 \mathrm{ml}$ blood sample was collected by retro-orbital bleeding under light anesthesia at $0,2,4,8,16$ and 24 hours after administration of 5-FU formulations or normal saline. At the end of the study, $2 \mathrm{ml}$ of blood was collected into centrifugation tubes, spun at $3000 \mathrm{rpm}$ for $10 \mathrm{~min}$ and the serum was separated and stored at $-20^{\circ} \mathrm{C}$. For the quantification of $5-\mathrm{FU}$, serum samples were filtered through $0.45 \mu \mathrm{m}$ membrane filter (Millipore) and the filtrate analyzed for drug content at
$266.6 \mathrm{~nm}$ using HPLC method as explained in References [41, 42]. All the experiments were performed at least in triplicate.

\section{In vivo organ distribution study}

The animals were euthanized by deep ether anesthesia at $0,2,4,8,16$, and 24 hours after administration of the drug-loaded hydrogel beads. The entire GI tract was then removed and mesenteric and fatty tissues were separated. The GI tract was separated into stomach, small intestine, cecum, and colon. These organs were homogenized by a microtissue homogenizer (Remi Ltd., Mumbai, India) using phosphate buffer ( $\mathrm{pH}$ 7.4) premixed with $1.5 \mathrm{ml}$ of acetonitrile and incubated for $45 \mathrm{~min}$. The samples were then centrifuged, supernatants collected and were appropriately diluted with the mobile phase, and the 5-FU content was determined by the HPLC method as described in References [41, 42].

\section{Statistical Analysis}

The Student t-test was used to perform statistical analysis and to determine the statistical significance. A value of $P$ less than 0.05 was considered statistically significant.

\section{Results and Discussion}

Currently, 5-FU delivery to patients is achieved mainly by the intravenous administration. However, it has been shown that the drug shows erratic absorption, inconsistent dosing and some side effects following i.v. administration $[5,6]$. With respect of addressing colon cancer, various efforts have been made to target drugs to colon using alternative routes of administration, including oral route, and employing different types of drug delivery systems as explained in the Introduction. The wide $\mathrm{pH}$ range of gastro intestinal tract causes difficulty for the delivery of drug to the colon and the hostile environment of the stomach causes polysaccharide-based delivery systems to disintegrate before reaching the colon.

Multiparticulate drug delivery systems of 5-FU based on dual concepts, namely a pH-dependent and microflora-activated system, have been shown to be useful in-vitro [43] while adequate pharmacokinetic and pharmacodynamics of a 5-FU colon-specific formulation is lacking. Consequently, in the present research Portulaca is used as a natural oral delivery matrix for targeting 5 -FU 

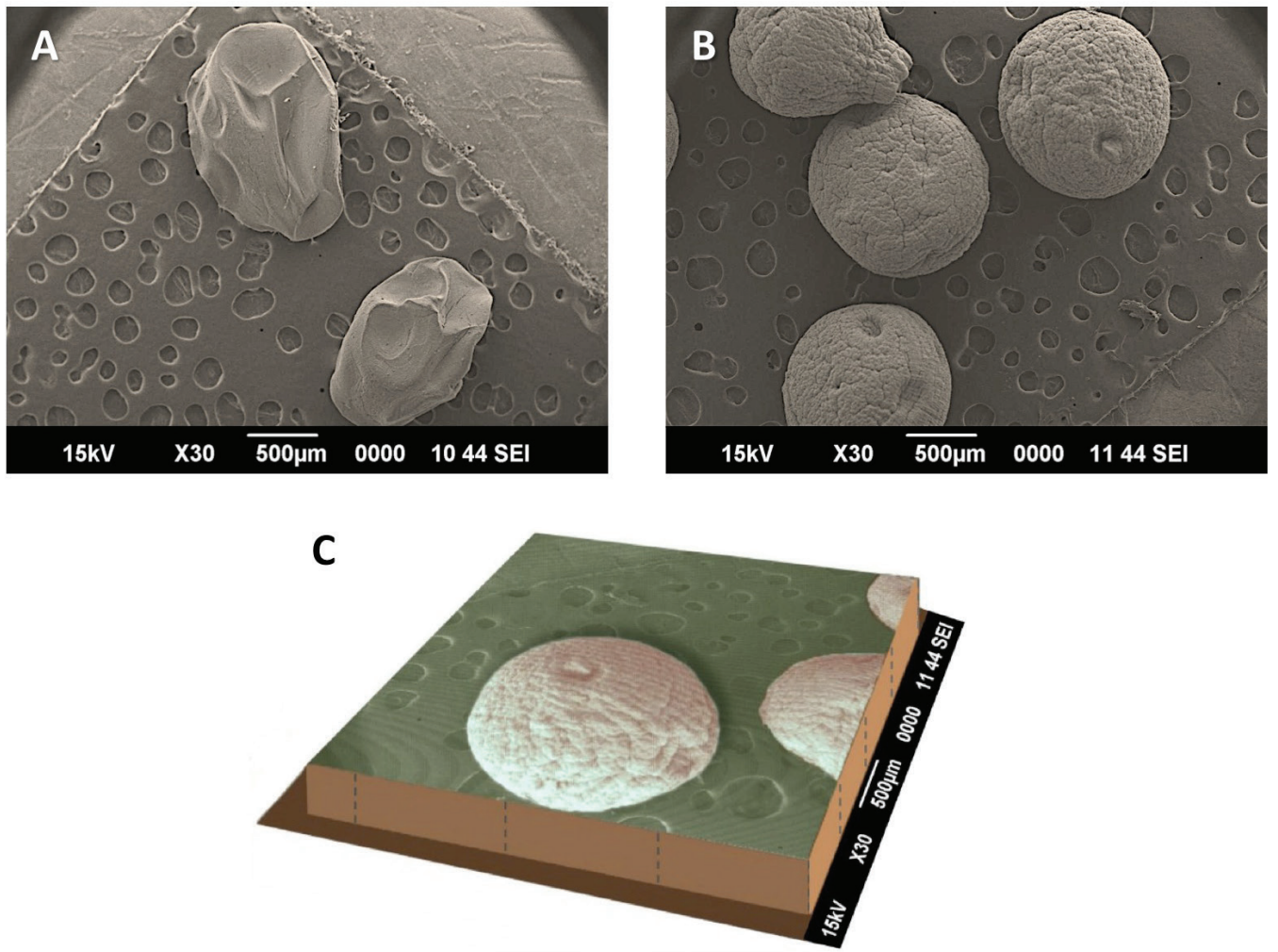

Figure 1: $(A)$ Beads made of alginate depicted as a control; $(B)$ Microspheres made of Portulaca-alginate-epichlorohydrin (double crosslinked hydrogel beads); and: $(C)$ Three dimensional representation of scanning electron micrograph depicting the overall shape and surface morphology of Portulaca-alginate-epichlorohydrin double crosslinked hydrogel beads encapsulating the anticancer agent 5 -fluorouracil.

to the colon and the safety and efficacy of the formulation was assessed in vitro and in vivo.

\section{Percentage yield}

The percentage yield of extraction of the mucilage from the Portulaca oleracea (Purslane) leaves was $8.4 \pm 1.7 \% \mathrm{w} / \mathrm{w}$. Furthermore, a high percentage yield of manufacturing hydrogel beads employing the Portulaca mucilage and other ingredients was obtained (i.e. $82 \% \mathrm{w} / \mathrm{w}$ ).

\section{Encapsulation efficiency}

A high value for 5-FU encapsulation efficiency was attained $(78 \% \mathrm{w} / \mathrm{w})$. This was an expected outcome due to the high level of crosslinking of the hydrophilic polymer matrix. This value is in line with the encapsulation efficiencies of 5-FU reported for an alginate-based hydrogel composite [44], and higher than the recently reported drug carrier technology Tocosome (i.e. 43-71\%) obtained by Mozafari and colleagues [17]. However, the drug encapsulation efficiency obtained in the present study is lower than the value obtained for a nanoliposomal formulation of 5-FU (up to 97\%) as reported by Elmeshad and coworkers [16].

\section{Morphology and particle size studies}

For morphological studies and size measurement of the Portulaca mucilage hydrogel beads, the scanning electron microscopy (SEM) technique was employed. SEM is one of the well-established and widely applied techniques for the analysis of shape, surface structure and size of different drug carriers [45,46]. Results of SEM analysis revealed spherical beads with a coarse surface morphology. Representative SEM images of the hydrogel beads are shown in Figure 1. The SEM images depict rough surface with flakes and wrinkles. These flakes and wrinkles might be caused by cross-linking of the polymeric network or partial collapse of the hydrogel beads during sample preparation for SEM analysis [47]. The particle size values of the microbeads prepared in the present study were in the range of 930 to $977 \mu \mathrm{m}$. 


\section{Cytotoxcity studies against HT-29 colon cancer cell line}

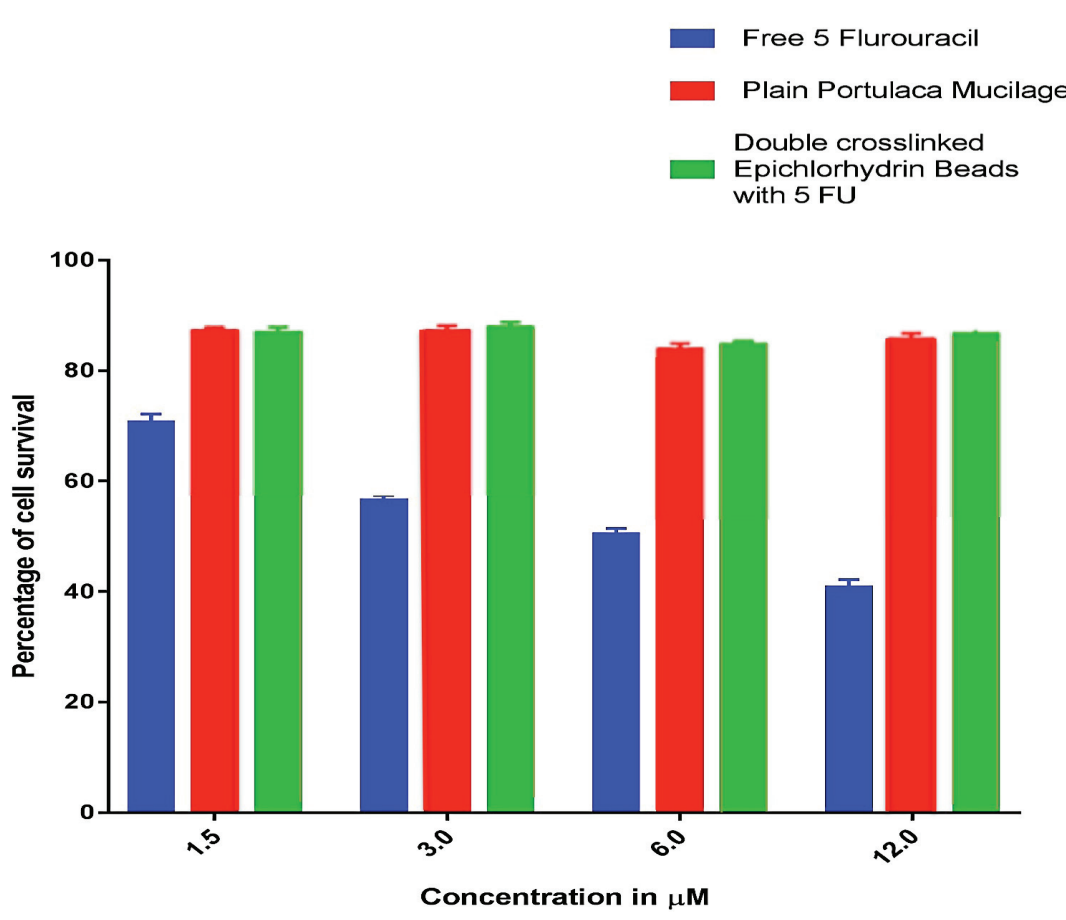

Figure 2: Cytotoxicity evaluation of the anticancer drug 5-FU, Portulaca mucilage and drug-loaded hydrogel bead formulation using a colon cancer cell line (HT-29).

\section{Cytotoxicity studies}

In-vitro cytotoxicity of hydrogel beads encapsulating 5-FU, as well as the Portulaca mucilage and un-encapsulated 5-FU solution was studied using HT-29 human colon cancer cell line by the MTT colorimetric assay. Cell viability percent for each sample was calculated and the results are depicted in Figure 2. Survival rates for the un-encapsulated drug was found to be lower compared to the Portulaca mucilage and drug-loaded hydrogel beads. The cytotoxicity trend of 5-FU was concentration dependent in the range tested. Results showed that Portulaca mucilage and microbead-encapsulated 5-FU formulations were less cytotoxic towards the cell line tested compared to the un-encapsulated drug. It is known that Portulaca is a plant with unique anticancer properties [34]. Therefore, combination of the extract of this plant with 5-FU provides a synergistic mechanism of action, as attested by the data obtained in this study (Figure 2).

\section{In vivo drug distribution study}

The pharmacokinetic parameters of the anticancer drug, encapsulated and un-encapsulated, are shown in Table 1. The un-encapsulated drug was prepared by dissolving 5-FU in carboxymethyl cellulose and designated as immediate release (IR) formulation, as explained under the Materials and Methods section. The plasma drug concentration / time profiles of the two formulations are entirely different. The maximum drug concentration in plasma $\left(\mathrm{C}_{\max }\right)$ was noticeably different for the two formulations, i.e. $8.96 \mu \mathrm{g} / \mathrm{ml}$ vs. $90.1 \mu \mathrm{g} / \mathrm{ml}$ for the hydrogel beads and IR formulations, respectively. Time to reach maximum drug concentration in plasma (i.e. $\mathrm{T}_{\max }$ ) was $16 \pm 1.2 \mathrm{~h}$ for the hydrogel beads, which was considerably higher than the $T_{\max }$ for the IR formulation (i.e. $1.2 \pm 0.81 \mathrm{~h}$ ). The mean residence time (MRT) was $14.08 \pm 2.34 \mathrm{~h}$ for the hydrogel beads, which was 4.26 times higher than that of the IR formulation $(3.30 \pm 0.23 \mathrm{~h})$. All of the values obtained for the pharmacokinetic parameters $\left(\mathrm{C}_{\max }, \mathrm{T}_{\max }\right.$, and MRT) for the two formulations were significantly different $(\mathrm{P}<$ $0.001)$. 
Table 1: Pharmacokinetic parameters of encapsulated 5-FU in the dual crosslinked epichlorohydrin / Portulaca mucilage hydrogel beads and the un-encapsulated (immediate release, IR) drug formulation in rat.

\begin{tabular}{lll}
\hline Parameters & 5-FU microspheres & IR formulation \\
\hline $\mathrm{C}_{\max }(\mu \mathrm{g} / \mathrm{ml})$ & 8.96 & 90.1 \\
$\mathrm{~T}_{\max }(\mathrm{h})$ & 16 & 1.2 \\
$\mathrm{AUC}(\mu \mathrm{g} / \mathrm{ml} / \mathrm{h})$ & 117.78 & 125.5 \\
Mean residence time (h) & 14 & 3.33 \\
Relative bioavailability (\%) & 93.6 & 100 \\
\hline
\end{tabular}

$\mathrm{C}_{\max }$ : maximum plasma concentration. $\mathrm{T}_{\max }$ : time to $\mathrm{C}_{\max }$.

AUC: area under-the-curve of the plasma concentration vs. time (0-24h).

Results also showed that drug absorption was sustained as indicated by a high $\mathrm{T}_{\max }$ value (Table 1). This finding suggests that the hydrogel beads, prepared by dual crosslinking of Portulaca mucilage, effectively prevent drug release in the upper part of the GI tract. Enzymatic degradation of the Portulaca polysaccharides by the enzymes of the colonic microflora is a slow process, which usually takes $12 \mathrm{~h}$. The encapsulated 5 -FU formulation showed $16 \mathrm{~h}$ drug release due to slow degradation of the polysaccharides. The IR formulation (un-encapsulated drug) showed the highest $\mathrm{C}_{\max }$ value that is because most of the 5-FU was absorbed in the upper part of the GI tract. The higher value of $T_{\max }$ obtained for the encapsulated drug indicates low systemic toxicity since less quantity of the drug is available systemically for interaction with nontarget sites. Consequently, encapsulation of the anticancer agent results in increasing the safety and efficacy index of the formulated hydrogel beads. The extended MRT of the hydrogel beads indicates that the drug was slowly and steadily released in the colon. These findings are in good agreement with the previously reported studies $[48,49]$. The ability of the formulated hydrogel beads to localize the drug in the colon can be explained considering the protective nature of the dual crosslinked Portulaca mucilage in the upper section of the GI tract. It appears that the drug was released from the hydrogel beads after arriving to the colon and being subject to the enzymatic degradation by the colonic microbial flora. It should be noted that conventional chemotherapy using 5 -FU has been recorded to result in severe side effects in the liver, digestive system and other body organs [50].
$\mathbf{A}$

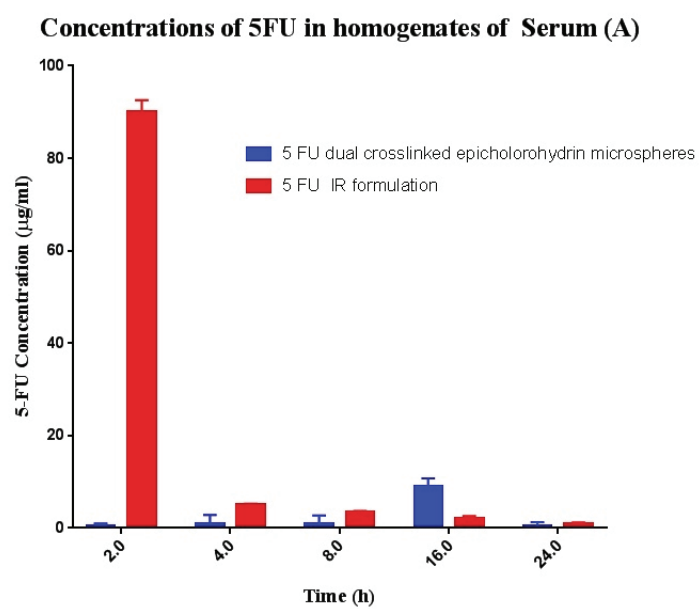

B

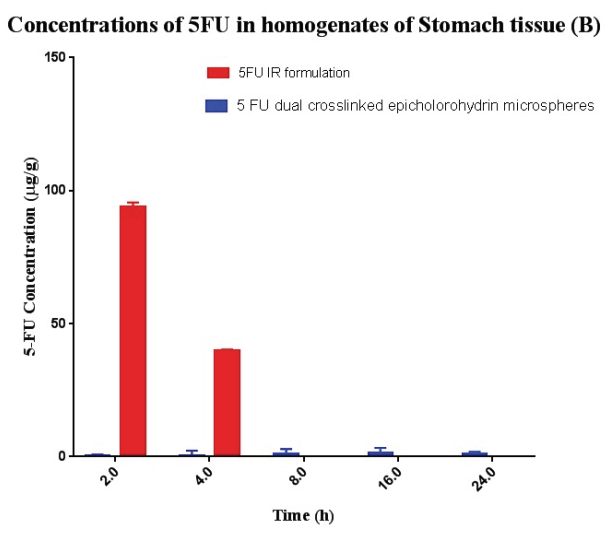

C

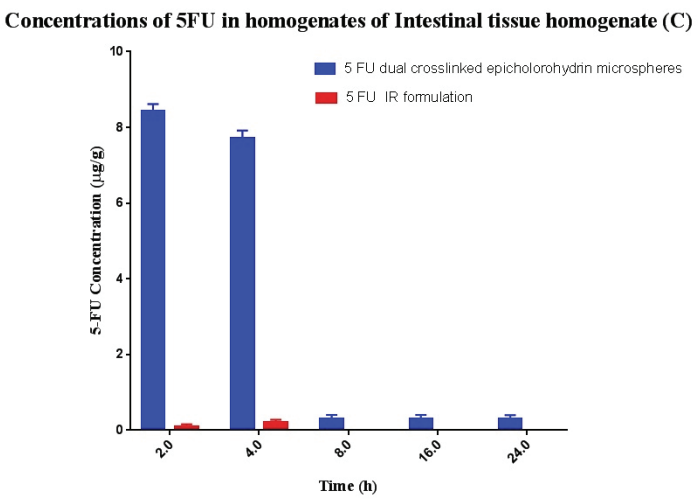

Figure 3: Drug concentration versus time profiles of encapsulated and free 5-FU in: (A) plasma; (B) stomach tissue homogenate; and (C) intestinal tissue homogenate after oral administration of colonspecific microspheres in Wistar rats. The immediate release (IR) formulation of 5-FU was prepared by suspending the drug in $0.5 \%$ $w / v$ sodium carboxymethylcellulose. Data are mean $\pm s$.d. $(n \geq 3)$. 
$\mathbf{A}$

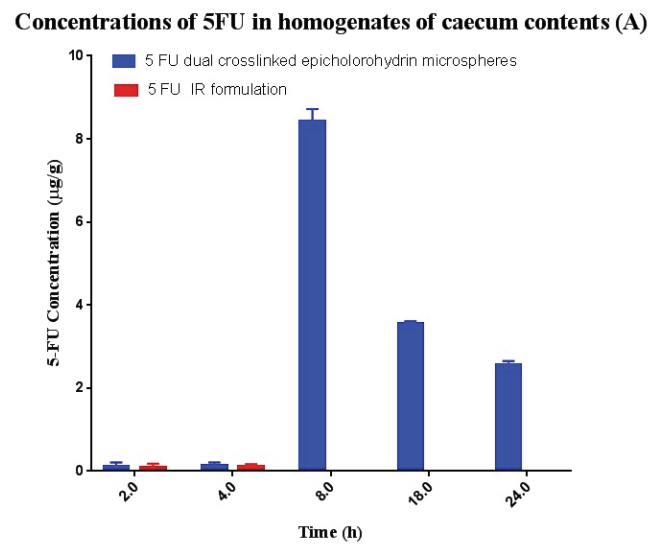

C

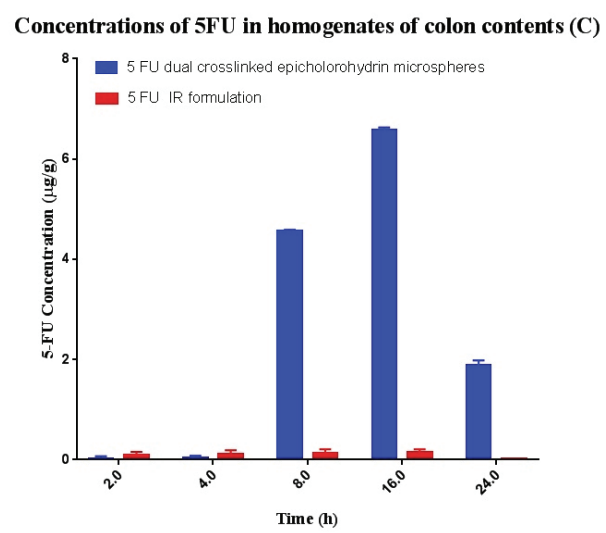

B

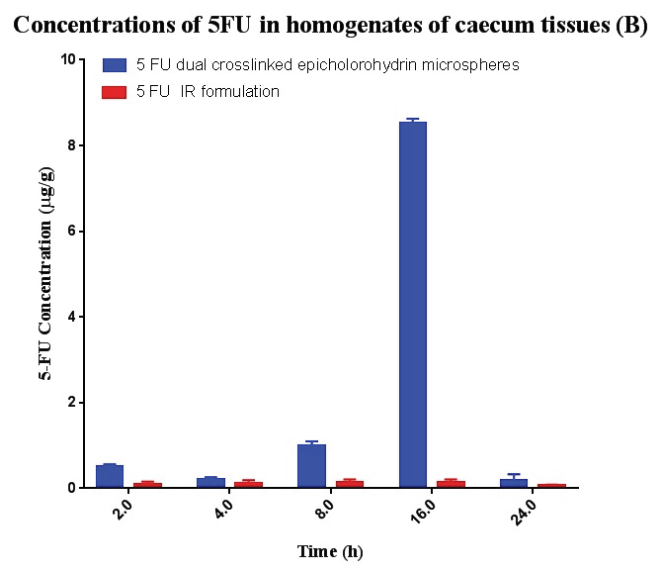

D

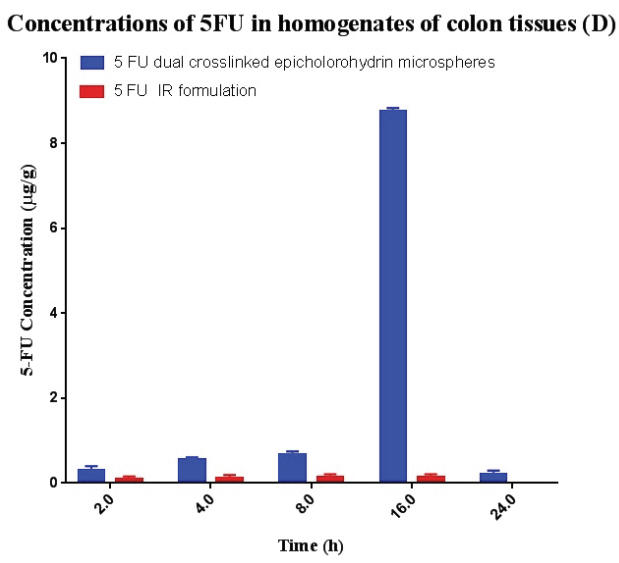

Figure 4: Concentration of un-encapsulated ad encapsulated 5-FU in homogenates of: (A) caecum content; (B) caecum tissue; (C) colon content; and (D) colon tissue after oral administration of the formulations. Data are mean \pm s.d. $(n \geq 3)$.

\section{Organ distribution study}

The organ distribution studies of the encapsulated 5-FU were carried out to evaluate the target specificity of the formulation in an animal model. Results indicated that maximum concentration of the un-encapsulated 5-FU (i.e. $94.5 \pm 5.4 \%$ ) was observed after $2 \mathrm{~h}$ in stomach when given orally. In the following hours, much less drug reached the small intestine, and afterwards no 5-FU was found in the colon. However, Portulaca mucilage-based hydrogel beads were observed and found intact in the upper part of the GI tract. Approximately $15.3 \%$ of the total encapsulated $5-\mathrm{FU}$ was released during its passage through the upper GI tract. After 8-10h, the maximum release of the encapsulated 5-FU was observed in the colon and a very insignificant amount of the drug was detected in the stomach and small intestine (Figure 3). Results attest that the formulated hydrogel beads are ideal systems for colon-specific drug delivery (Figure 4).

\section{Conclusion}

The anticancer drug 5-FU is a therapeutic agent with a very short half-life and significant side effects particularly when given in conventional dosage forms. In an attempt to improve the therapeutic efficacy and safety of the drug, a novel hydrogel bead formulation was developed for localized delivery of 5-FU to the colon. The drug delivery system was prepared by dual crosslinking of Portulaca mucilage using epichlorohydrin. The formulated microspheres were analyzed for their in vitro and in vivo safety and efficacy. The in vitro study indicated the anticancer efficacy of the formulations. The pharmacokinetic study revealed enhanced bioavailability of the therapeutic agent, while the GI distribution studies indicated localized drug concentration in the colon. The novel dual crosslinked Portulaca microspheres prepared in this study are proven to be a promising oral delivery system to combat colon cancer. Further studies 
are required to establish long-term stability and clinical efficacy of the formulation.

Acknowledgements: The authors are thankful to the Sinhgad Technical Education Society and Dr. S. D. Sawant, Principal, Smt. Kashibai Navale College of Pharmacy, Kondhwa, Pune and Dr. Prabhakar Kore Basic Science Research Centre, KLE University, Belgaum for providing required research facilities.

Animal handling ethics : The animal experimental protocols performed in this study were approved by the Institutional Ethical Committee for Care and Use of Laboratory Animals and they were handled according to the code of ethics in research, training, and testing of drugs. The ethics committee approval number is: SKNCOP/ IAEC/120/2017.

Conflict of interest: Authors state no conflict of interest.

\section{References}

1. Ishikawa T, Sekiguchi F, Fukase Y, Sawada N, Ishitsuka H. Positive correlation between the efficacy of capecitabine and doxifluridine and the ratio of thymidine phosphorylase to dihydropyrimidine dehydrogenase activities in tumors in human cancer xenografts. Cancer Res., 1998, 58 (4), 685-690.

2. Meropol NJ. Oral fluoropyrimidines in the treatment of colorectal cancer. European J. Cancer., 1998, 34 (10), 1509-1513.

3. Sargent DJ, Goldberg RM, Jacobson SD, Macdonald JS, Labianca R, Haller DG, Shepherd LE, Seitz JF, Francini G. A pooled analysis of adjuvant chemotherapy for resected colon cancer in elderly patients. New England J. Medicine, 2001, 345 (15), 1091-1097.

4. Rudy BC, Senkowski BZ. Fluorouracil. In: Florey K, ed. Analytical Profiles of Drug Substances. New York: Academic Press, 1973; pp. 221-244.

5. Djordjevic MV, Brunnemann KD, Hoffmann D. The need for regulation of carcinogenic Nnitrosamines in oral snuff. Food Chem. Toxicol., 1993, 31 (7), 497-501.

6. Herrmann R. Systemic treatment of colorectal cancer. European J. Cancer., 1993, 29 (4), 583-586.

7. Holland SK, Bergman AM, Zhao Y, Adams ER, Pizzorno G. 19F NMR monitoring of in vivo tumor metabolism after biochemical modulation of 5 -fluorouracil by the uridine phosphorylase inhibitor 5-benzylacyclouridine. Magnetic Resonance in Medicine. 1997, 38 (6), 907-916.

8. Van der Wilt CL, Smid K, Aherne GW, Noordhuis P, Peters GJ. Biochemical mechanisms of interferon modulation of 5 -fluorouracil activity in colon cancer cells. European J. Cancer., 1997, 33 (3), 471-478.

9. Chabner BA, Fine RL, Allegra C), Yeh GW, Curt GA. Cancer chemotherapy: progress and expectations. Cancer, 1984, 54 (S2), 2599-2608.
10. Fraile RJ, Baker LH, Buroker TR, Horwitz J, Vaitkevicius VK. Pharmacokinetics of 5 -fluorouracil administered orally, by rapid intravenous and by slow infusion. Cancer Research. 1980, 40 (7), 2223-2228.

11. Au JL, Gunnarsson LC. Absorption of 5'-Deoxy-5-fluorouridine from Colon. Pharm. Res., 1989, 6 (4), 323-327.

12. Tuchman M, Ramnaraine ML, O'Dea RF. Effects of uridine and thymidine on the degradation of 5 -fluorouracil, uracil, and thymine by rat liver dihydropyrimidine dehydrogenase. Cancer Res., 1985, 45 (11 Part 1), 5553-5556.

13. Chandrashekar NS, Rani RS. Microprocessor in controlled transdermal drug delivery of anti-cancer drugs. Journal of Materials Science: Materials in Medicine., 2009, 20 (1), 189.

14. Elmeshad AN, Tadros MI. Transdermal delivery of an anti-cancer drug via w/o emulsions based on alkyl polyglycosides and lecithin: design, characterization, and in vivo evaluation of the possible irritation potential in rats. AAPS Pharmscitech., 2011, 12 (1), 1-9.

15. Kaiser N, Kimpfler A, Massing U, Burger AM, Fiebig HH, Brandl M, Schubert R. 5-Fluorouracil in vesicular phospholipid gels for anticancer treatment: entrapment and release properties. Int. J. Pharm., 2003, 256 (1-2), 123-131.

16. Elmeshad AN, Mortazavi SM, Mozafari MR. Formulation and characterization of nanoliposomal 5 -fluorouracil for cancer nanotherapy. J. Liposome Res., 2014, 24 (1), 1-9.

17. Mozafari MR, Javanmard R, Raji M. Tocosome: Novel drug delivery system containing phospholipids and tocopheryl phosphates. Int. J. Pharm., 2017, 528 (1-2), 381-382.

18. Torchilin VP. Polymer-coated long-circulating microparticulate pharmaceuticals. J. Microencapsul., 1998, 15 (1), 1-9.

19. Yang JC, Haworth L, Sherry RM, Hwu P, Schwartzentruber DJ, Topalian SL, Steinberg SM, Chen HX, Rosenberg SA. A randomized trial of bevacizumab, an anti-vascular endothelial growth factor antibody, for metastatic renal cancer. New England J. Med., 2003, 349 (5), 427-434.

20. Chourasia MK, Jain SK. Polysaccharides for colon targeted drug delivery. Drug Delivery. 2004, 11 (2), 129-148.

21. Torchilin VP. Targeted pharmaceutical nanocarriers for cancer therapy and imaging. The AAPS Journal, 2007, 9 (2), E128-147.

22. Ghorab MM, Ragab FA, Heiba HI, Agha HM. Synthesis of Some Novel Sulfonamides Containing Biologically Active Alkanoic Acid, Acetamide, Thiazole, and Pyrrole Moieties of Expected Antitumor and Radiosensitizing Activities. J. Basic Appl. Chem., 2011, 1, 8-14.

23. Rammohan A, Sathyanesan J, Rajendran K, Pitchaimuthu A, Perumal SK, Srinivasan UP, Ramasamy R, Palaniappan R, Govindan M. A gist of gastrointestinal stromal tumors: A review. World J. Gastrointestinal Oncology, 2013, 5 (6), 102.

24. Rai M, Kon K, Ingle A, Duran N, Galdiero S, Galdiero M. Broadspectrum bioactivities of silver nanoparticles: the emerging trends and future prospects. Applied Microbiol. Biotech., 2014, 98 (5), 1951-1961.

25. Sareen R, Nath K, Jain N, Dhar KL. Curcumin loaded microsponges for colon targeting in inflammatory bowel disease: fabrication, optimization, and in vitro and pharmacodynamic evaluation. BioMed Res. Int., 2014; 2014.

26. Zeng WG, Zhou ZX, Hou HR, Liang JW, Zhou HT, Wang Z, Zhang $\mathrm{XM}, \mathrm{Hu}$ JJ. Outcome of laparoscopic versus open resection for rectal cancer in elderly patients. J. Surgical Res., 2015, 193 (2), 613-618. 
27. Zhao Y, He M, Zhao L, Wang S, Li Y, Gan L, Li M, Xu L, Chang PR, Anderson DP, Chen Y. Epichlorohydrin-cross-linked hydroxyethyl cellulose/soy protein isolate composite films as biocompatible and biodegradable implants for tissue engineering. ACS Applied Materials \& Interfaces, 2016, 8 (4), 2781-2795.

28. Lamprecht A, Yamamoto H, Takeuchi H, Kawashima Y. Microsphere design for the colonic delivery of 5-fluorouracil. J. Controlled Rel., 2003, 90 (3), 313-322.

29. Semde AJ, Moes MJ, Devleeschouwer M, Amighi K, In vitro evaluation of epichlorohydrin cross-linked pectin as colonspecific drug delivery carriers. STP Pharma Sciences, 2002, 12, 293-298.

30. Semde AJ, Moes MJ, Devleeschouwer M, Amighi K, Synthesis and enzymatic degradation of epichlorohydrin cross-linked pectins. Drug Dev. Ind. Pharm., 2003, 29, 203-213.

31. Zhang W, Ji X, Sun C, Lu X, Fabrication and characterization of macroporous epichlorohydrin crosslinked alginate beads as protein adsorbent. Prep. Biochem. Biotechnol., 2013, 43, 431-444.

32. Mishra, S.K. Pathak, K. Formulation and evaluation of oil entrapped gastroretentive floating gel beads of loratadine, Acta Pharm. 58 (2008) 187-197)

33. P. Gacesa, N.J. Russell, The structure and properties of alginate, in P. Gacesa, N.J. Russell (Eds.), Pseudomonas infection and alginates, Springer, Netherlands, 1990, pp. 29-249.

34. Asnani GP, Bahekar J, Kokare CR. Development of novel $\mathrm{pH}$-responsive dual crosslinked hydrogel beads based on Portulaca oleracea polysaccharide-alginate-borax for colon specific delivery of 5-fluorouracil. J. Drug Deliv. Sci. Tech. 2018, 48, 200-208.

35. Patil JS, Kamalapur MV, Marapur SC, Kadam DV. Ionotropic gelation and polyelectrolyte complexation: the novel techniques to design hydrogel particulate sustained, modulated drug delivery system: a review. Digest J. Nanomaterials Biostructures, 2010, 5 (1), 241-248.

36. Anuradha K, Bangal P, Sakunthala Madhavendra S. Structural characterization and water turbidity removing efficacy of Portulaca mucilage-alginate (PMA) beads. Desalination and Water Treatment, 2016, 57 (10), 4386-4397.

37. Awasthi R, Kulkarni GT, Ramana MV, Pinto TD, Kikuchi IS, Ghisleni DD, de Souza Braga M, De Bank P, Dua K. Dual crosslinked pectin-alginate network as sustained release hydrophilic matrix for repaglinide. Int. J. Biological Macromolecules, 2017, 97, 721-732.

38. Bishop M, Shahid N, Yang J, Barron AR. Determination of the mode and efficacy of the cross-linking of guar by borate using MAS 11B NMR of borate cross-linked guar in combination with solution 11B NMR of model systems. Dalton Trans., 2004, 17, 2621-2634.
39. Katti, K. Kannan, R. and Katti, K. Stabilized, biocompatible gold nanoparticles and environ-friendly method for making same, US patent 2009/0074674 A1, March 19, 2009.

40. Preezel NC, Webling DD. The length and mucosal surface area of the small and large gut in young rat. J. Anat., 1971, 108, 295296.

41. Li X. "Cage" Nano and Micro-particles for Biomedical Applications (Doctoral dissertation, Paris Saclay) 2017.

42. Rai G, Yadav AK, Jain NK, Agrawal GP. Enteric-coated epichlorohydrin crosslinked dextran microspheres for sitespecific delivery to colon. Drug Dev. Ind. Pharm., 2015, 41 (12), 2018-2028.

43. Jain A, Gupta Y, Jain SK. Potential of calcium pectinate beads for target specific drug release to colon. J. Drug Target., 2007, 15, 285-294.

44. Wu C, Li C, Zhang X, Cheng C, Wang J. An alginate-based hydrogel composite obtained by UV radiation and its release of 5-fluorouracil. Polymer Bulletin, 2018, 1-16.

45. Danaei M, Dehghankhold M, Ataei S, Hasanzadeh Davarani F, Javanmard R, Dokhani A, Khorasani S, Mozafari MR. Impact of particle size and polydispersity index on the clinical applications of lipidic nanocarrier systems. Pharmaceutics, 2018, 10 (2), 57.

46. Khosravi-Darani K, Pardakhty A, Honarpisheh H, Rao VM, Mozafari MR. The role of high-resolution imaging in the evaluation of nanosystems for bioactive encapsulation and targeted nanotherapy. Micron, 2007, 38 (8), 804-818.

47. Pasparakis G, Bouropoulos N. Swelling studies and in vitro release of verapamil from calcium alginate and calcium alginate-chitosan beads. Int. J. Pharm., 2006, 323 (1-2), 34-42.

48. Rahman Z, Kohli K, Zhang SQ, Khar RK, Ali M, Charoo NA, Tauseef M, Shamsher AA, Mohammed NN, Repka MA. In-vivo evaluation in rats of colon-specific microspheres containing 5-fluorouracil. J. Pharm. Pharmacol., 2008, 60 (5), 615-623.

49. Wei H.; Qing D, De-Ying C, Bai X, Li-Fang F. Study on colonspecific pectin/ethylcellulose film-coated 5 -fluorouracil pellets in rats. Int. J. Pharm., 2008, 348, 35-45.

50. Sonis ST, Elting LS, Keefe D, Peterson DE, Schubert M, Hauer-Jensen M, Bekele BN, Raber-Durlacher J, Donnelly JP, Rubenstein EB. Perspectives on cancer therapy induced mucosal injury. Cancer, 2004, 100 (S9), 1995-2025. 